\title{
Insight, Self Esteem and Response Styles in Patients with Bipolar Disorder: its Relationship with Hallucinations and Delusions
}

\author{
Sonia M. El-Sayad \\ Lecturer of Psychiatric and Mental Health Nursing/ Faculty of Nursing / Port-Said University
}

\begin{abstract}
Background: Bipolar disorder is a cyclic illness, in which patient alternating between manic and depressive episodes. It is a mental illness that can affect person's relationships, level of performance and quality of life.

Aim: The present study aimed at assessing the correlation among self esteem, insight, response styles, delusions and hallucinations among depressed as well as manic patients.

Method: Eighty seven patients diagnosed with bipolar disorder and located in the in-patient Port-Said psychiatric hospital were participated in this research. In order to collect data for the present study the following tools were used; Beck Cognitive Insight Scale, State Self Esteem Scale, Response Styles Questionnaire and psychotic Symptoms Rating Scale.

Results: Both delusions and hallucinations correlated positively with total scores of self esteem, self reflection and distraction; on the other hand, they were negatively correlated with self certainty and rumination. Moreover, there were significant positive correlations found among dimensions of self esteem, self certainty, distraction response, engaging in dangerous activities response, hallucinations and delusions.

Recommendations: Encouraging and assisting patients with bipolar disorders to use problem solving instead of rumination and risky behaviors in stressful situations is recommended. Hallucinations have greater significant variances in patient' levels of self esteem, insight and styles of responses, thus dealing with hallucination and managing it is also highly recommended in order to develop better levels of patient' self esteem and insight.
\end{abstract}

\section{Introduction}

Bipolar disorders could be labeled as a cyclic illness, in which patient alternating between mania and depression. It is characterized be the occurrence of at least one manic episode followed by depressive one, and in between, the patient reported to be returned to normal life. The most common features exhibited during the manic episode are; heightened mood, excitement, irritability, pressure of speech, poor insight and psychotic symptoms. On the other hand, in depressive episode patient characterized by depressed mood, psychomotor retardation, slow thinking, poor judgment, low self esteem and- unlike mania- decreased evidence of delusions and hallucinations. During both manic and depressive episodes, patients probably experience psychosis, in which patients cannot differentiate between reality and fantasy, and this psychosis characterized by delusions and hallucinations. Delusions can be defined as a false fixed belief that is not consistent with person's education and culture as well as cannot be corrected by logic or reason (Kumari, Chaudhury and Kumar, 2013), while hallucination is a false perception without external stimuli, that have different categories, stages and types. Both delusions and hallucinations are amongst the most prevalent features of psychosis, which have significant effects on patients' condition, response and improvement.

Previous literatures revealed that there are some environmental etiological factors have its evidenced impact on the development of psychiatric disorders, among these significant factors are; self esteem and poor social adjustment (Daskalopoulou et al, 2002; Pardoen, Bauwen, Tracy, Martin and Mendlewicz, 1993). Self esteem is a global concept; it comprised both self worth and self evaluation by others. It is considered an essential element in psychological health; its disturbance has its hazardous effects on person's quality of life and may consequently result in psychological problems. Various researches explored the relationship between self esteem and psychological disturbance and reported that anxiety and depression were among the highly correlated disorders. On this context, previous researches pointed out that self esteem is correlated significantly with depression (Deb and Bhattacharejee, 2009; Hayward, Wong, Bright and Lam, 2002; Cox et al, 2000), and even between episodes of depression and mania, self esteem found to be low as compared to control groups (Nilsson, Jorgensen, Craig, Straarup and Licht, 2010). Other study looked at self esteem discrepancies between depressed and manic patients found that damaged self esteem observed in depression with no occurrence in mania (Pavlickova, Turnbull and Bentall, 2014). Self esteem was also found to assist in the development of delusions and maintenance of psychotic symptoms.

On the other hand it was found that the experience of psychological disturbances may itself result in low self esteem (Meaden, Keen, Aston, Barton, Bucci, 2013; BrichWood, Meaden, Trower, Gilbert, Plaistow, 2000). Despite of multiple studies and results but the relationship still uncertain, as there were studies reflected 
Insight, Self Esteem and Response Styles in Patients with Bipolar Disorder: its Relationship ....

that self esteem could be an etiological factor, and others stated that it is an outcome factor. Literatures showed significant correlations between self esteem and delusions; suggesting that low self esteem is correlated significantly with persecutory type of delusion, while high self esteem correlated with grandiosity type (Warman and Lysaker, 2001). Moreover, high levels of paranoid ideation and suspiciousness were associated with low self-esteem (Warman, Lysaker, Leutdk, Martin, 2010). Other literatures and studies linked self esteem with hallucinations and stated that the content of hallucinations may be affected by self esteem, as the study of Barrowclough at al, 2003 which revealed that negative self appraisal related to voices was correlated with negative self esteem. Furthermore, Peters, Williams, Cooke, Kuipers, 2012 and Fannon et al, 2009 mentioned in their study that low self esteem in depressed patients was related significantly with patients' perception of voices as uncontrollable and dominating. Moreover, depressed patients with low self esteem had more severe hallucinations and high level of stress (Smith et al, 2006). But on the other hand, studies as DeVylder and Hilimire, 2015 and Bowins and Shugar, 1998 reported that hallucination was independently related with self esteem.

Theories about insight have been based on its roots on the studies of positive and negative symptoms among schizophrenic patients; and as a result few researches considered the relationship between insight and delusions among bipolar disorders patients. Insight is a complex phenomenon; encompasses dimensions as awareness of illness, symptoms and consequently the need for treatment. Researchers reported that people with psychiatric disorders tend to have poor insight, for example, the study of Erikson and Lysaker, 2012 revealed that poor insight correlated significantly with schizophrenia and specifically in the presence of psychotic symptoms.

On the other hand, Beck defined and related cognitive insight to both self reflectiveness and self certainty, which reflect the patient's ability to observe the mental productions of his $\backslash$ her beliefs and consequently consider explanations and overconfidence in those beliefs. Therefore, Beck Cognitive Insight Scale based on two subscales; self reflectiveness and self certainty. Engh et al, 2007 in their study compared between schizophrenic and bipolar patients in relation to cognitive insight, and pointed out that self reflectiveness and self certainty were correlated significantly among bipolar disorder patients and slightly correlated in schizophrenic ones. One of the remarkable finding is the result of Werf-Eldering, Meer, Holthausen and Aleman, 2011 study about insight in bipolar disorders, as they noticed in their study that better insight was associated with higher depressive symptoms. They explained this result that cognitive functioning and psychotic features are independently associated with insight.

Using other measure namely Insight Scale for affective Disorders Da Selva et al, 2015 studied insight in bipolar disorders while focusing on two dimensions; insight about condition and insight about symptoms, their results showed that worse insight about condition and symptoms was observed among manic patients. In the same consequence, other studies as Bressi, Porcellana, Marinaccio, Nocito, Ciabatti, Magri, 2012; Dell'Osso, Pini, Cassano, Mastrocinque, Seckinger, Saettoni, 2002; Dell'Osso, Pini, Tundo, Sarno, Musetti, Cassano, 2000 confirmed that insight was poor in both mania and depression, with poorer evidence in manic episodes.

The way bipolar disorders patients respond to their symptoms, supposed to be correlated with the duration of illness. Response styles theory is one of few theories studied the role of coping strategies in psychological wellbeing among persons, Nolen-Hoeksema, 1991 proposed that rumination; a cognitive response style that involves passively brooding about one's mood, would lead to increases in depressive symptoms, while distraction and problem-solving would lead to decrease in symptoms. Further studies proved this assumption and relate response styles with depressive symptoms and noted that rumination, particularly, low problem solving and lower levels of distraction increase depressive symptoms (Pavlickova et al, 2013; Hilt, McLaughlin, Nolen-Hoeksema, 2010; Abela, Aydin, Auerbach, 2007). On the other hand, Thomas, Knowles, Bentall, 2007 reported in their study that manic patients reported greater use of active-coping and risk-taking response styles as compared to the depressed, remitted and healthy controls.

Considering the previously mentioned literature, there were no much studies concerning the study of the interrelationship between self esteem, insight and response styles in bipolar disorders patients. Thus the contribution of this study will be aimed at assessing some significant variables (self esteem, insight, response styles) and relate it with symptoms of delusions and hallucinations in depressed and manic patients.

The findings of the present research will hopefully redound in clarifying the role of psychotic features in determining level of self esteem and insight in patients, as well as, the style of responses exhibited by patients in stressful situations. Thus those findings may guide nurses in identifying the importance of management of delusions and hallucinations which may contribute to developing better levels of self esteem and insight. Moreover, it can also help nurses in enabling patients to recognize their responses in stress and consequently, be able to modify it to more healthier and effective style. Comparing between depressed and manic patient in relation to the studying variables, will also give a clear clarification of the significance of those variables, and in turn, help nurses in identifying critical data about patients and may contribute to more easier and comprehensive assessment of patients. 


\section{Objectives of the study}

The present research aims to reveals the correlation among self esteem, insight, response styles, delusions and hallucinations among depressed as well as manic patients. In order to attain this aim, there are sub objectives clarified as follows: firstly is to determine the level of self esteem among bipolar disorders patients and secondly is to measure level of insight among the studied subjects. One of the limited studied variables is the response styles among patients, thus Thirdly, it is aimed to identify the styles of responses exhibited by bipolar disorders patients in situations of stress and finally to correlate between self esteem, insight, response styles, delusions and hallucinations among bipolar disorders patients.

\subsection{Participants and Procedure}

\section{Methods}

A Descriptive Correlational study design was followed in this research in order to achieve its aim. The present study was carried out at the inpatient psychiatric units in Port Said Psychiatric Health hospital. The hospital is affiliated to the Ministry of Health; it provides care to psychiatric patients, from three governorates namely Port Said, El- Ismailia and El -Suez. The hospital capacity is 150 beds divided into six inpatient psychiatric units, three units for male patients'; two units for female patients; and the last one is a child unit.

All patients entered the hospital during the period from 1 February 2015 to 1 August 2015, and diagnosed with bipolar disorders were included in the study $(\mathrm{N}=87)$. The researcher reviewed all patients' charts in each ward in order to identify the diagnosis of psychiatric patients. Then the study conducted using the interview technique, in which each patient was interviewed individually for 1-2 sessions according to patient's condition in order to establish rapport and trust therapeutic relationship. The researcher started to collect data 3 days per week with average 3-5 hours. A number of 1-2 subjects were interviewed per day. Each interview lasted for 25-45 minutes, depending on the response of the interviewee. The researcher provided patients with the needed information and purpose of the study then fills in the questionnaire.

\subsection{Measures}

The following questionnaire and scales were used in collecting data for the present study:

A questionnaire was developed by the researcher in order to assess socio-demographic characteristics of the patients such as gender, age and residence, in addition to data concerning their clinical history such as diagnosis, duration of illness and the number of previous admissions.

Beck Cognitive Insight Scale; it was developed by Beck, Baruch, Balter, Steer and Warman, 2004 and used in this study in order to evaluate self reflectiveness of the patients and overconfidence of their interpretation of experiences and resistance to feedback. The scale is consisted of 15 statements answered on 4 points likert scale $(0=$ do not agree at all to $3=$ completely agree); and measures two subscales namely; self reflectiveness ( 9 items) and self certainty (6 items). High scores of self-reflectiveness and low scores on subscale self-certainty is considered as normal.

State Self Esteem Scale; is a scale to measure self esteem, it was developed by Heatherton, Polivy, 1991. It consists of 20 statements on 5 points likert scale ( $1=$ not at all to $5=$ extremely). High scores reflect high levels of self esteem in relation to three dimensions namely; performance, social and appearance self esteem.

Response Styles Questionnaire. The original questionnaire was developed by Nolen-Hoeksema, 1991, and included 71 items measures responses of rumination, distractibility and problem solving in different situations. The questionnaire was then revised and slightly modified by Thomas and Bentall (2002), in which statements measuring rumination and distraction were retained and added 6 items regarding dangerous activities subscale. Thus, the revised tool is consisted of 48 statements; 23 rumination items, 11 items for distraction, 4 problem solving statements and finally 10 items for dangerous activities. It was then used the present study to assess the extent to which patients used different styles of responses. Patients asked to rate their answers on range from almost always $(=3)$ to almost never $(=0)$.

Psychotic Symptoms Rating Scale. It is 17 items scale, measuring multi dimensions of delusions and hallucinations, answered on 5- point likert scale ranging from $0=$ absent to $4=$ extremely endorsed. It consists of 11 items measures hallucinations and 6 items related to delusions. Symptoms are assessed in relation to a week earlier, in which high scores indicate high severity of symptoms (Drake, Haddock, Tarrier, Bentall, Lewis, 2007).

\subsection{Data Analysis}

Descriptive statistics of the present study was measured by means, minimum, maximum, skewness and kurtosis values. Independent sample t-test was used in order to assess the difference between the study groups in relation to the studied variables (i.e. difference between males and females in regard to insight and self esteem). Pearson's coefficient correlations were also used to explore the association between the variables. Multivariate Analysis of Variance (MANOVA) was used in order to tests whether or not the independent grouping variable simultaneously explain statistically significant amount of variance in the dependent variable, which eventually represents the significant variance of delusions and hallucinations on insight, self esteem level and response 
Insight, Self Esteem and Response Styles in Patients with Bipolar Disorder: its Relationship ....

styles. P-value and $95 \%$ confidence intervals was illustrated. Statistical significance was set on .05 while highly statistical significance was set on .01. IBM SPSS Statistics version 20 was used for all analysis.

\subsection{Ethical Considerations}

The agreement of General Secretariat of Mental Health Research Unit was taken to conduct research in Port- Said Psychiatric Health Hospital. The director of Psychiatric Health Hospital and patients were informed about the purpose of the study, then the subjects consent was taken, they were informed about their right to not participate in the study and that their answers will not be taken against them, as it will be used just for the purpose of the study. Also they were reassured regarding privacy and confidentiality.

\section{Results}

Table 1: reveals the sociodemographic and clinical characteristics of the studied patients. As shown from the table, more than half of the patients (54.4\%) were aged between 18-28 years, followed by $33.1 \%$ aged from 28 to 38 years old and more than two thirds were female (75.9\%). It was also noticed that almost quarter of the subjects were single (24.1\%) and $25.2 \%$ were divorced. $32.1 \%$ of the patients reported to have a preparatory level of education, compared to $12.6 \%$ had university level. Looking to the clinical data, the table presents that $39.0 \%$ of patients diagnosed with manic episode and $61.0 \%$ were experiencing depressive episode. More than two thirds of patients $(77.0 \%)$ reported that they had had previous psychiatric hospitalization history, and more than half (52.9\%) of patients stated that they did not receive family visits during the last two months.

Table (1): Socio demographic and clinical characteristics of the studied patients

\begin{tabular}{|c|c|c|}
\hline Data & Frequency & $\%$ \\
\hline \multicolumn{3}{|l|}{ Age } \\
\hline$<18$ & 7 & 8.0 \\
\hline $18-28$ & 47 & 54.4 \\
\hline $28-38$ & 29 & 33.1 \\
\hline$>38$ & 4 & 4.5 \\
\hline \multicolumn{3}{|l|}{ Gender } \\
\hline Male & 21 & 24.1 \\
\hline Female & 66 & 75.9 \\
\hline \multicolumn{3}{|l|}{ Marital Status } \\
\hline Single & 21 & 24.1 \\
\hline Married & 43 & 49.4 \\
\hline Divorced & 22 & 25.2 \\
\hline Widowed & 1 & 1.1 \\
\hline \multicolumn{3}{|l|}{ Level of Education } \\
\hline Illiterate & 7 & 8.0 \\
\hline Read and Write & 20 & 22.9 \\
\hline Preparatory level & 28 & 32.1 \\
\hline Secondary level & 21 & 24.1 \\
\hline University Level & 11 & 12.6 \\
\hline \multicolumn{3}{|l|}{ Working Status } \\
\hline Not & 20 & 22.9 \\
\hline Craftsman & 15 & 17.2 \\
\hline Professional & 1 & 1.1 \\
\hline Employee & 5 & 5.7 \\
\hline Housewife & 46 & 52.8 \\
\hline \multicolumn{3}{|l|}{ Diagnosis } \\
\hline Mania & 34 & 39.0 \\
\hline Depression & 53 & 61.0 \\
\hline \multicolumn{3}{|c|}{ Previous Hospitalization } \\
\hline Yes & 67 & 77.0 \\
\hline No & 20 & 23.0 \\
\hline \multicolumn{3}{|l|}{ Family Visits } \\
\hline Yes & 41 & 47.1 \\
\hline No & 46 & 52.9 \\
\hline
\end{tabular}

Table 2: represents descriptive statistics of self esteem, level of insight, response styles, hallucinations and delusions among bipolar patients. Among the three dimensions of self esteem, the social dimension recorded the highest mean $(\mathrm{M}=22.74 ; \mathrm{SD}=6.11)$. Concerning patients' level of insight, it was found that self reflection reported with a high mean $(\mathrm{M}=21.86 ; \mathrm{SD}=8.49)$. Rumination as a response style was the highly reported style among the subjects $(M=22.64 ; S D=12.48)$, followed by engaging in dangerous activities as a response in dealing with a stressful situations (i.e. smoking, substance abuse) with $\mathrm{M}=12.40$ and $\mathrm{SD}=7.72$. Finally regarding symptoms of hallucinations and delusions as reported by the studied patients, it was noticed to be slightly similar in their mean scores $(\mathrm{M}=13.8$ and $\mathrm{M}=13.1$ respectively). 
Insight, Self Esteem and Response Styles in Patients with Bipolar Disorder: its Relationship ....

Table (2): Minimum, maximum, means, standard deviations, skewness and kurtosis of the studied variables $(\mathrm{N}=$ 87)

\begin{tabular}{|l|l|l|l|l|l|l|}
\hline Variables & Min & Max & M & SD & Skewness & Kurtosis \\
\hline Performance (SSES) & 7.00 & 34.00 & 18.6207 & 10.02235 & .379 & -1.690 \\
\hline Social (SSES) & 15.00 & 33.00 & 22.7471 & 6.11179 & .474 & -1.400 \\
\hline Appearance (SSES) & 6.00 & 30.00 & 16.4023 & 9.43085 & .462 & -1.708 \\
\hline Self Reflection (BCIS) & 10.00 & 33.00 & 21.8621 & 8.49647 & -.411 & -1.737 \\
\hline Self Certainty(BCIS) & 6.00 & 23.00 & 13.8851 & 5.75149 & .393 & -1.649 \\
\hline Rumination(RSQ) & 2.00 & 42.00 & 22.6437 & 12.48625 & -.265 & -1.500 \\
\hline Distraction (RSQ) & 2.00 & 23.00 & 11.4483 & 6.62230 & .257 & -1.462 \\
\hline Problem Solving(RSQ) & .00 & 9.00 & 4.4483 & 2.02173 & .073 & -.693 \\
\hline Dangerous Activities(RSQ) & 2.00 & 24.00 & 12.4023 & 6.72977 & .222 & -1.441 \\
\hline Hallucination & .00 & 42.00 & 13.8966 & 16.18788 & .512 & -1.580 \\
\hline Delusions & 3.00 & 24.00 & 13.1724 & 6.19866 & .145 & -1.427 \\
\hline
\end{tabular}

Note: SSES= State Self Esteem Scale; BCIS= Beck Cognitive Insight Scale; RS= Response Styles Questionnaire.

As regard table 3: it is clear from the results that there were significant positive correlations found at $\mathrm{P}$ value $<0.01$ between dimensions of self esteem and self certainty, distraction, engaging in dangerous activities, hallucinations and delusions. While self esteem was correlated significantly and negatively with self reflection and rumination. Furthermore, self reflection as well as rumination were correlated negatively with dangerous activities, hallucinations and delusions $(\mathrm{r}=-.895, \mathrm{r}=-.954, \mathrm{r}=-.837$ and $\mathrm{r}=-.831, \mathrm{r}=-.891, \mathrm{r}=-.829$ respectively for both). On the other hand, there were no significant correlations observed between problem solving response style and the different studied variables.

Table (3): Correlations between self esteem, level of insight, response styles, hallucinations and delusions among the studied patients.

\begin{tabular}{|c|c|c|c|c|c|c|c|c|c|c|c|c|}
\hline Variables & 1 & 2 & 3 & 4 & 5 & 6 & 7 & 8 & 9 & 10 & 11 & 12 \\
\hline Performance (SSES) & - & & & & & & & & & & & \\
\hline Social (SSES) & $.916^{* *}$ & - & & & & & & & & & & \\
\hline Appearance (SSES) & $.961^{* *}$ & $.942^{* *}$ & - & & & & & & & & & \\
\hline Total Self Esteem & $.984^{* *}$ & $.964^{* *}$ & $.989 * *$ & - & & & & & & & & \\
\hline Self Reflection (BCIS) & $-.951^{* *}$ & $-.906^{* *}$ & $-.968^{* *}$ & $-.965^{* *}$ & - & & & & & & & \\
\hline Self Certainty(BCIS) & $.938^{* *}$ & $.893^{* *}$ & $.951^{* *}$ & $.950^{* * *}$ & $-.970 * *$ & - & & & & & & \\
\hline Rumination(RSQ) & $-.877^{* *}$ & $-.849 * *$ & $-.910^{* * *}$ & $-.900 * *$ & $.909 * *$ & $-.908 * *$ & - & & & & & \\
\hline Distraction (RSQ) & $.907^{* *}$ & $.871^{* *}$ & $.910^{* *}$ & $.917^{* *}$ & $-.911^{* *}$ & $.904^{* *}$ & $-.893^{* *}$ & - & & & & \\
\hline $\begin{array}{l}\text { Problem } \\
\text { Solving(RSQ) }\end{array}$ & .046 & .035 & .028 & .037 & .002 & .010 & .004 & -.011 & - & & & \\
\hline $\begin{array}{l}\text { Dangerous } \\
\text { Activities(RSQ) }\end{array}$ & $.863^{* *}$ & $.838^{* *}$ & $.885^{* *}$ & $.882^{* *}$ & $-.895^{* *}$ & $.888^{* *}$ & $-.831^{* * *}$ & $.810^{* * *}$ & -.019 & - & & \\
\hline Hallucination & $920 * *$ & $.886 * *$ & $.942^{* *}$ & $.938^{* *}$ & $-.954 * *$ & $923^{* * *}$ & $-.891^{* *}$ & $.877^{* * *}$ & -.002 & $.892^{* * *}$ & - & \\
\hline Delusions & $.827^{* *}$ & $.822^{* *}$ & $.870^{* *}$ & $.858^{* *}$ & $-.837^{* *}$ & $.825^{* *}$ & $-.829 * *$ & $.796^{* *}$ & .031 & $.801^{* *}$ & $.859^{* *}$ & - \\
\hline
\end{tabular}

Note: SSES= State Self Esteem Scale; BCIS= Beck Cognitive Insight Scale; RS= Response Styles Questionnaire. **. Correlation is significant at the 0.01 level (2-tailed).

In order to attain the objectives of the study, table 4 reflects the comparison between manic and depressed patients in relation to self esteem, insight, response styles, hallucinations and delusions. As presents in the table, manic patients scored high in different dimensions of self esteem, self certainty, distraction style, problem solving, engaging in dangerous activities as well as symptoms of hallucinations and delusions. As regard depressed patients, self reflection and rumination mean scores were high among them as compared to manic patients $(M=$ 28.52; $\mathrm{SD}=1.58$ and $\mathrm{M}=31.88 ; \mathrm{SD}=5.13$ respectively). The table also reveals that there were statistical significant differences observed between manic and depressed patients in relation to different studied variables except problem solving response style.

Table (4): Comparison between manic and depressed patients in relation to the studied variables.

\begin{tabular}{|c|c|c|c|c|c|c|}
\hline & \multicolumn{2}{|c|}{ Manic Patients $N=(34)$} & \multicolumn{2}{|c|}{ Depressed Patients $N=(55)$} & \multirow[t]{2}{*}{$\mathbf{t}$} & \multirow[t]{2}{*}{ Sig. } \\
\hline & $\mathbf{M}$ & SD & $\mathbf{M}$ & SD & & \\
\hline Performance (SSES) & 30.6176 & 2.34863 & 10.9245 & 2.85448 & 33.574 & $.000 *$ \\
\hline Social (SSES) & 29.8235 & 2.64541 & 18.2075 & 1.89492 & 23.849 & $.000 *$ \\
\hline Appearance (SSES) & 27.8824 & 2.22608 & 9.0377 & 1.58068 & 46.158 & $.000 *$ \\
\hline Total Self Esteem & 88.32 & 6.22 & 38.16 & 3.76 & 46.882 & $.000 *$ \\
\hline Self Reflection (BCIS) & 11.4706 & 1.23669 & 28.5283 & 1.58847 & -53.100 & $.000 *$ \\
\hline Self Certainty(BCIS) & 20.8235 & 1.24245 & 9.4340 & 1.43459 & 38.024 & $.000 *$ \\
\hline Rumination(RSQ) & 8.2353 & 3.70142 & 31.8868 & 5.13158 & -23.253 & $.000 *$ \\
\hline Distraction (RSQ) & 19.0294 & 2.06684 & 6.5849 & 2.85168 & 21.990 & $.000 *$ \\
\hline Problem Solving(RSQ) & 4.5000 & 2.19158 & 4.4151 & 1.92588 & .190 & .850 \\
\hline Dangerous Activities(RSQ) & 19.9118 & 2.88536 & 7.5849 & 3.01556 & 18.917 & $.000 *$ \\
\hline Hallucination & 33.1765 & 5.96693 & 1.5283 & 3.43961 & 31.386 & $.000 *$ \\
\hline Delusions & 19.7941 & 2.77193 & 8.9245 & 3.40728 & 15.577 & $.000 *$ \\
\hline
\end{tabular}

Note: SSES= State Self Esteem Scale; BCIS= Beck Cognitive Insight Scale; RS= Response Styles Questionnaire. 
Insight, Self Esteem and Response Styles in Patients with Bipolar Disorder: its Relationship ....

Table 5: compares between patients who had frequent family visits and patients who had not in regard to self esteem, level of insight, different response styles, hallucinations and delusions. As clear from the table, there were no statistical significant differences observed between the two groups in relation to the studied variables, except with delusions at $\mathrm{p}$ - value $<0.05(\mathrm{t}=2.081)$. In the same context of comparison, table 6 compares between male and female patients in relation to the studied variables. Statistically significant differences were observed between the two groups and all dimensions of self esteem and insight, as well as hallucinations and delusions were found at $\mathrm{p}$ - value $<0.01$. Concerning the response styles of the subjects, there were significant differences between males as well as females and all styles except with problem solving in which $\mathrm{t}=-.051$ and $\mathrm{P}$ - value $=.959$.

Table (5): Comparison between patients having and patients not having frequent family visits in relation to the studied variables.

\begin{tabular}{|c|c|c|c|c|c|c|}
\hline & \multicolumn{2}{|c|}{$\begin{array}{c}\begin{array}{c}\text { Patients having frequent } \\
\text { family visits } \\
\mathrm{N}=(\mathbf{4 1})\end{array} \\
\end{array}$} & \multicolumn{2}{|c|}{$\begin{array}{c}\text { Patients not having } \\
\text { frequent family visits } \\
\mathrm{N}=(\mathbf{4 6}) \\
\end{array}$} & \multirow[t]{2}{*}{$\mathbf{t}$} & \multirow[t]{2}{*}{ Sig. } \\
\hline & $\mathbf{M}$ & SD & $\mathbf{M}$ & SD & & \\
\hline Performance (SSES) & 20.2927 & 10.33500 & 17.1304 & 9.60233 & 1.479 & .143 \\
\hline Social (SSES) & 23.4634 & 6.70111 & 22.1087 & 5.53063 & 1.032 & .305 \\
\hline Appearance (SSES) & 18.2927 & 9.37082 & 14.7174 & 9.26082 & 1.787 & .077 \\
\hline Total Self Esteem & 62.0488 & 26.10168 & 53.9565 & 23.77857 & 1.513 & .134 \\
\hline Self Reflection (BCIS) & 20.8049 & 8.70121 & 22.8043 & 8.29088 & -1.097 & .276 \\
\hline Self Certainty(BCIS) & 14.5854 & 6.01654 & 13.2609 & 5.49519 & 1.073 & .286 \\
\hline Rumination(RSQ) & 21.0732 & 13.15559 & 24.0435 & 11.82644 & -1.109 & .271 \\
\hline Distraction (RSQ) & 12.5610 & 6.68599 & 10.4565 & 6.47630 & 1.490 & .140 \\
\hline Problem Solving(RSQ) & 4.5610 & 1.76137 & 4.3478 & 2.24319 & .489 & .626 \\
\hline Dangerous Activities(RSQ) & 13.3659 & 6.61346 & 11.5435 & 6.78792 & 1.265 & .209 \\
\hline Hallucination & 17.0000 & 16.93812 & 11.1304 & 15.13878 & 1.707 & .091 \\
\hline Delusions & 14.6098 & 5.99949 & 11.8913 & 6.15441 & 2.081 & $.040^{*}$ \\
\hline
\end{tabular}

Note: SSES= State Self Esteem Scale; BCIS= Beck Cognitive Insight Scale; RS= Response Styles Questionnaire.

Table (6): Comparison between male and female patients in relation to the studied variables.

\begin{tabular}{|c|c|c|c|c|c|c|}
\hline & \multicolumn{2}{|c|}{$\begin{array}{c}\text { Male Patients } \\
\quad \mathrm{N}=(\mathbf{2 1})\end{array}$} & \multicolumn{2}{|c|}{$\begin{array}{c}\text { Female Patients } \\
\mathrm{N}=(66)\end{array}$} & \multirow[t]{2}{*}{$\mathbf{t}$} & \multirow[t]{2}{*}{ Sig. } \\
\hline & M & SD & M & SD & & \\
\hline Performance (SSES) & 13.0000 & 5.35724 & 20.4091 & 10.51735 & -3.094 & $.003 *$ \\
\hline Social (SSES) & 19.5238 & 3.07602 & 23.7727 & 6.48737 & -2.891 & $.005 *$ \\
\hline Appearance (SSES) & 9.9524 & 5.16213 & 18.4545 & 9.57911 & -3.881 & $.000^{*}$ \\
\hline Total Self Esteem & 42.4762 & 12.31105 & 62.6364 & 26.19726 & -3.399 & $.001 *$ \\
\hline Self Reflection (BCIS) & 26.6190 & 5.56306 & 20.3485 & 8.73806 & 3.088 & $.003 *$ \\
\hline Self Certainty(BCIS) & 10.9524 & 3.76133 & 14.8182 & 5.97922 & -2.786 & $.007 *$ \\
\hline Rumination(RSQ) & 31.0476 & 9.77996 & 19.9697 & 12.11480 & 3.809 & $.000 *$ \\
\hline Distraction (RSQ) & 7.7143 & 4.80773 & 12.6364 & 6.70622 & -3.113 & $.003 *$ \\
\hline Problem Solving(RSQ) & 4.4286 & 2.03891 & 4.4545 & 2.03191 & -.051 & .959 \\
\hline Dangerous Activities(RSQ) & 8.6190 & 4.38721 & 13.6061 & 6.92127 & -3.103 & $.003 *$ \\
\hline Hallucination & 2.9048 & 9.20817 & 17.3939 & 16.40626 & -3.849 & $.000 *$ \\
\hline Delusions & 8.1429 & 4.81960 & 14.7727 & 5.73731 & -4.781 & $.000 *$ \\
\hline
\end{tabular}

Note: SSES= State Self Esteem Scale; BCIS= Beck Cognitive Insight Scale; RSQ= Response Styles Questionnaire.

In order to tests whether or not hallucinations and delusions simultaneously explain statistically significant amount of variance in self esteem, level of insight and response styles among the studied patients. The results showed in table 7 reveals that Wilks' Lambda test showed significant effect of only hallucinations $(\mathrm{F}=1.23$; $\mathrm{p}=0.05)$ on the studied variables. In more details, table 8 showed that hallucinations had significant effects on performance self esteem, social self esteem, appearance self esteem, self certainty and engaging in dangerous activities $(\mathrm{F}=2.683,2.275,2.722,4.433,3.605,3.228$ respectively $)$. One of the striking results observed in this study is that delusions have no statistical significant effect on the studied variables.

Table (7): Multivariate test showing the effect of hallucination and delusions on self esteem, level of insight and response style among the patients

\begin{tabular}{|l|l|l|l|}
\hline & \multicolumn{1}{|c|}{$\begin{array}{c}\text { Wilks' Lambda test } \\
\text { Value }\end{array}$} & \multicolumn{1}{c|}{ F } & Sig. \\
\hline Hallucinations & .014 & 1.236 & $.050^{*}$ \\
\hline Delusions & .031 & .966 & .600 \\
\hline
\end{tabular}


Insight, Self Esteem and Response Styles in Patients with Bipolar Disorder: its Relationship ....

Table (8): Multivariate Analysis of Variance (MANOVA) showing the effect of hallucination and delusions on self esteem, level of insight and response style among the patients

\begin{tabular}{|c|c|c|c|c|c|c|}
\hline & Dependent Variables & $\begin{array}{l}\text { Type III Sum } \\
\text { of Squares }\end{array}$ & df & Mean Square & $\mathbf{F}$ & Sig. \\
\hline \multirow[t]{9}{*}{ Hallucinations } & Performance (SSES) & 790.954 & 20 & 39.548 & 2.683 & $.003^{*}$ \\
\hline & Social (SSES) & 317.542 & 20 & 15.877 & 2.275 & $.011 *$ \\
\hline & Appearance (SSES) & 466.328 & 20 & 23.316 & 2.722 & $.003 *$ \\
\hline & Self Reflection (BCIS) & 598.972 & 20 & 29.949 & 4.433 & $.000 *$ \\
\hline & Self Certainty(BCIS) & 286.307 & 20 & 14.315 & 3.605 & $.000^{*}$ \\
\hline & Rumination(RSQ) & 735.335 & 20 & 36.767 & 1.123 & .361 \\
\hline & Distraction (RSQ) & 344.669 & 20 & 17.233 & 1.640 & .083 \\
\hline & Problem Solving(RSQ) & 80.257 & 20 & 4.013 & .890 & .600 \\
\hline & Dangerous Activities(RSQ) & 438.078 & 20 & 21.904 & 3.228 & $.001 *$ \\
\hline \multirow[t]{9}{*}{ Delusions } & Performance (SSES) & 222.844 & 20 & 11.142 & .756 & .748 \\
\hline & Social (SSES) & 117.743 & 20 & 5.887 & .843 & .652 \\
\hline & Appearance (SSES) & 95.597 & 20 & 4.780 & .558 & .921 \\
\hline & Self Reflection (BCIS) & 55.404 & 20 & 2.770 & .410 & .983 \\
\hline & Self Certainty(BCIS) & 63.672 & 20 & 3.184 & .802 & .698 \\
\hline & Rumination(RSQ) & 371.407 & 20 & 18.570 & .567 & .915 \\
\hline & Distraction (RSQ) & 124.458 & 20 & 6.223 & .592 & .898 \\
\hline & Problem Solving(RSQ) & 47.269 & 20 & 2.363 & .524 & .941 \\
\hline & Dangerous Activities(RSQ) & 211.371 & 20 & 10.569 & 1.557 & .107 \\
\hline
\end{tabular}

\section{Discussion}

Delusions and hallucinations have been reported in many studies as diagnostic measures of psychosis in many psychiatric disorders, people who have bipolar disorders are usually experience those symptoms in either mood congruent or mood incongruent. As, in depressive episodes, delusions may reflect feelings of inadequacy and worthlessness and in manic episodes patients may hear voices commanding him/ her, or belief that he/ she is being controlled. Various researchers studied psychosis and recommended that patients should be hospitalized for its risky consequences on both patients and others. This research paper aimed at assessing hallucinations and delusions among bipolar disorder patients and relates it with levels of self esteem and insight, as well as the exhibited response styles among those patients during their illness episodes.

High mean scores of self esteem dimensions showed in relation to social self esteem, followed by performance then appearance self esteem. This result may be due to the group participation of patients at the hospital in making different activities, which may enhance their relationship with each others, and consequently, improve the way the patients are perceived by others, which in turn affects patient's social self esteem (Nilsson, Jorgensen, Craig , Straarup, Licht, 2010; Deb, Bhattacharjee, 2009). Furthermore, patients with high self esteem level noticed to have lower tendency to use rumination and instead use distraction as a response style. This result is a realistic finding because it is hypothesized that patient with high self esteem may not ruminate and in state choose to divert their attention from annoying or depressive feelings (Pavlickova, Turnbull, MyinGermeys, Bentall, 2015; Pavlickova et al, 2013; Johnson, McKenzie, McMurrich, 2008). In the same context, self esteem observed to be high among manic patients, patients who had frequent family visits and female patients. Previous researches also reflected that inflated self esteem observed among manic patients (e.g, Park, Ryu, Ha, Lee, Choi, Ha, 2014) as well as female subjects (e.g, Pavlickova, Turnbull, Bentall, 2014).

Concerning insight, the present study showed that the highest mean scores of insight were observed in self reflection, which entails patients' objectivity, reflectiveness and openness to experience towards their illness. Indeed, this mean score did not reflect high normal scores; instead it presented as a higher score, and this result may due to the higher number of depressed patients in this study. Other studies approved this finding and reported in their study that self reflection was high among depressed patients ( e.g. Riggs, Grant, Perivoliotis, Beck, 2012; Werf-Eldering, Meer, Burger, Holthausen, Nolen, Aleman, 2011; Warman, Lysaker, Martin, 2007 ; Colis, Steer, Beck, 2006). Moreover, Beck and his colleges proposed that the significant cognitive problem of psychotic features among psychiatric patients is that they are unable to be detached from their cognitive distortions (Beck et al, 2004). Self certainty as a dimension measuring cognitive insight of subjects in the present study, revealed by its items patients' certainty of being right about their misconceptions and distorted ideas which supposedly affect patients' clinical insight and enhance sustain of delusions ( Cooke et al, 2010).

The present study results showed that self certainty was high among female subjects and patients who had frequent family visits as well as significant differences found between manic and depressed patients in relation to their insight. This finding may be explained that family members still detached from patients even when visiting them frequently, due to their poor knowledge about psychiatric disorders and its symptoms (e.g, distorted thoughts), moreover, family not participate in the patients' plan of care, thus they not follow therapeutic care and handling with their relative patients. Furthermore, most of female subjects of the present study diagnosed with mania, which characterized by high self certainty about their faulty thoughts. But this result is inconsistent 
Insight, Self Esteem and Response Styles in Patients with Bipolar Disorder: its Relationship ....

with the result of (Engh et al, 2007; Yen, Chen, Yeh, Ker, Yang, Yen, 2004) who stated in their study that male subjects had poorer insight than females and there were no significant differences in the mean scores of insight among the studied bipolar groups. But the present study was in line with the results of (Da Silva et al, 2015; Cassidy, 2010; Yen, Chen, ko, Yen, Huang, 2007) who reported in their results that there were significant differences between bipolar groups suggesting that depressed patients had better insight.

In addition, results of the present study showed that self reflection was correlated negatively with most of the studied variables (e.g, self esteem, distraction), while self certainty was correlated significantly and positively with all the studied variables (such as self esteem, distraction, problem solving) except rumination. It is not a surprising result, because pathological high self esteem and overconfidence are supposed to be increasing when patients' level of certainty towards their thoughts (distorted) increased and vice versa. This result was in accordance with the results of (Story, 2004; Owens, Stryker, Goodman , 2006) which referred that low self esteem correlated with low scores of self certainty.

Rumination is a behavioral and an emotion -focused coping style in response to depressed mood which focus patients' attention on their depressive feelings and its consequences, while distraction is another response style characterized by diversion of depressed thoughts and replacing it with more neutral or pleasant thoughts. Thus, rumination assumed to increase the severity and duration of depression, while distraction hypothesized to alleviate depression (Pavlickova, Turnbull, Myin-Germeys, Bentall, 2015; Ghaznavi and Deckersbach, 2012; Perich, Manicavasagar, Mitchell, ball, 2011; Roelofs et al, 2010; Thomas, Knowles, Tai, , Bentall, 2007). The present study findings revealed that patients tend to ruminate when feeling distressed if they have low self esteem and depression as well as if they were male. On this context, Ghaznavi, Deckersbach, 2012 review researches and studies on rumination among bipolar patients and proposed that rumination increased in depressive episodes among bipolar patients. Moreover, the results of the studies of (Silveira, Kauer-Sant'Anna, 2015; Bentall et al, 2011; Deckersbach et al, 2011; Van der Gucht, Morriss, Lancaster, Kinderman, Bentall, 2009; Johnson, McKenzie, McMurrich, 2008) were consistent with this result.

On the other hand, distraction, problem solving and dangerous activities as response styles exhibited by the study subjects when feeling depressed, were correlated positively and significantly with self esteem and self certainty. This is a reasonable result, persons with high self esteem expected to use problem solving in stressful situation and if not succeeded they may resort to distract their attention. It can be also assumed that highly esteem persons refrain from limits on their behaviors, like engaging in new experience and can use risky behaviors when experiencing new situations. This result is in accordance with the study of Abela, Brozena, Haigh, 2002 who examined the response styles theory of depression and found that low self esteem mediate the relationship between rumination and depression. While in the results of the study conducted by Pavlickova et al, 2015 stated that low self esteem triggered risky- taking behaviors.

One of the interesting findings of this study is that hallucination has a significant variance with self esteem, insight level as well as using dangerous activities in dealing with stress, while delusion has no significant variance. This result was congruent with the results of Kumari, Chaudhury and Kumar, 2013; who assessed delusions and hallucinations in affective and non- affective disorders patients; and they claimed that this result may be due to the fact that amount of content and degree of hallucinations and delusions may contribute to the compromise of the insight, they stated that "hallucinations and delusions lead to loosening of "normal" everyday associations and difficulties with reasoning. Thus it may not be surprising that when these symptoms are present patients have deficient awareness of their illness". On the other hand, the study of Ben-Zeef, Morris, Swendsen and Granholm, 2012 disagreed with this result and reported that the occurrence, conviction and stress of delusions showed significant variance with negative self esteem and poor insight.

\section{Conclusion and Recommendations}

This study aimed at assessing self esteem, insight as well as response styles, and its relationship with delusions and hallucinations in bipolar disorders patients. It can be concluded that both delusions and hallucinations correlated positively with total scores of self esteem, self reflection and distraction; on the other hand, they were negatively correlated with self certainty and rumination. Moreover, there were significant positive correlations found among dimensions of self esteem, self certainty, distraction response, engaging in dangerous activities response, hallucinations and delusions. Furthermore, it has been noticed that hallucinations had significant effects on performance self esteem, social self esteem, appearance self esteem, self certainty and engaging in dangerous activities. Encouraging and assisting patients with bipolar disorders to use problem solving instead of rumination and risky behaviors in stressful situations is recommended. Hallucinations have greater significant variances in patient' levels of self esteem, insight and styles of responses, thus dealing with hallucination and managing it is also highly recommended in order to develop better levels of patient' self esteem and insight. Further researches investigating the effect of different dimensions of psychosis on such variables as insight and mood are also recommended. 


\section{References}

[1]. Abela J, Aydin C, Auerbach A. (2007): Responses to depression in children: Reconceptualizing the relation among response styles. Journal of Abnormal Child Psychology;P.p. 35:913-937.

[2]. Abela J, Brozena K, Haigh E. ( 2002): An examination of the response styles theory of depression in third- and seventh-grade children: a short-term longitudinal study. Journal of Abnormal Child Psychology. Oct;30(5):P. 515-27.

[3]. Barrowclough C, Tarrier N, Humphreys L, Ward J, Gregg L, Andrews B. (2003): Self esteem in schizophrenia: Relationships between self evaluation family attitudes and symptomatology. Journal of Abnormal Psychology,P.p. 112: 92-99.

[4]. Beck AT, Baruch E, Balter JM, Steer RA, Warman D M (2004): A new instrument for measuring insight: the Beck Cognitive Insight Scale. Schizophrenia Research.68(2-3):P. 319-29.

[5]. Ben-Zeef D, Morris S, Swendsen J,Granholm E. (2012): Predicting the occurrence, conviction, distress and disruption of different delusional experiences in the daily life of people with schizophrenia. Schizophrenia Bulletin, 38 (4): 826-837.

[6]. Bentall R, Myin-Germeys I, Smith A, Knowles R,. Jones S, Smith T, Tai S. (2011): Hypomanic Personality, Stability of Self-Esteem and Response Styles to Negative Mood. Clinical Psychology and Psychotherapy (2011).

[7]. Bowins B and Shugar G. (1998): Delusions and self esteem. Canadian Journal of Psychiatry,P. 43.

[8]. Bressi C, Porcellana M, Marinaccio PM, Nocito EP, Ciabatti M, Magri L (2012): The association between insight and symptoms in bipolar inpatients: an Italian prospective study. Eur Psychiatry,P. 27:619-24.

[9]. Brichwood M, Meaden A, Trower P, Gilbert P, Plaistow J. (2000): The power and omnipotence of voices: Subordination and entrapment by voices and significant others. Psychiatric Medicine,P.p. 30: 337- 344.

[10]. Cassidy F . (2010): Insight in bipolar disorder: relationship to episode subtypes and symptom dimensions. Neuropsychiatric Disorders Treatment. 2010;P.p. 6: 627-631.

[11]. Colis $M$, Steer $R$, Beck A. (2006): Cognitive insight in inpatients with psychotic, bipolar, and major depressive disorders. Journal Psychopathology Behavior Assessment; P.p.28:242-249.

[12]. Cooke M, Peters E, Fannon D, Aesen I, Kuipers E, Kumari V. (2010): Cognitive insight in psychosis: The relationship between self-certainty and self-reflection dimensions and neuropsychological measures. Psychiatry Research. 2010 Jul 30; 178(2):P.p. 284-289.

[13]. Cox B, Rector N, Bagby $R$, Swinson R, Levitt A, Joffe $R$ (2000): Is self criticism unique for depression?: A comparison with social phobia. Journal of Affect Disorders, P.p. 57, 223:228.

[14]. Da Silva R, Mograbi D, Evelyn V, Camelo E, Bifano J, Wainstok M, Silva Silveira L, Cheniaux E. (2015): Insight in bipolar disorder: a comparison between mania, depression and euthymia using the Insight Scale for Affective Disorders. Trends Psychiatry Psychotherapy, 37( 3):P. 152-6.

[15]. Daskalopoulou E, Dikeos D, Papadimitriou G, Souery D, Blairy S, Massat I, Mendlewicz J, Stefanis C. (2002): Self esteem social adjustment and suicidality affective disorders. European Psychiatry. 17,P.p. 265:271

[16]. Deb S, Bhattacharjee A. (2009): Self-Esteem of Depressive Patients. Journal of the Indian Academy of Applied Psychology July 2009, Vol. 35, No. 2,P.p. 239-244.

[17]. Deckersbach T, Hölzel BK, Eisner LR, Stange JP, Peckham AD, Dougherty DD, Rauch SL, Lazar S, Nierenberg AA. (2011): Mindfulness-based Cognitive Therapy for Non remitted Patients with Bipolar Disorder. CNS Neuroscience \& Therapeutics.

[18]. Dell'Osso L, Pini S, Cassano GB, Mastrocinque C, Seckinger RA, Saettoni M. (2002): Insight into illness in patients with mania, mixed mania, bipolar depression and major depression with psychotic features. Bipolar Disorders, 4:P. 315-22.

[19]. Dell'Osso L, Pini S, Tundo A, Sarno N, Musetti L, Cassano GB.(2000): Clinical characteristics of mania, mixed mania, and bipolar depression with psychotic features. Compr Psychiatry, 41:P. 242-7.

[20]. DeVylder J and Hilimire M.(2015): Suicide risk, stress sensitivity and self esteem among young adults reporting auditory hallucinations. Health Social Work Journal. Aug;40(3):P. 175-81.

[21]. Drake R, Haddock $\boldsymbol{G}$, Tarrier N, Bentall R, Lewis $\boldsymbol{S}$ (2007): . The psychotic symptom rating scales (PSYRATS): their usefulness and properties in first episode psychosis. Schizophrenia Research, 89(1-3):P.p.119-122.

[22]. Engh J, Friis S, Birkenaes A, Jonsdottir H, Ringen P, Ruud T, Sundet K, Opjordsmoen S, Andreassen O. ( 2007): Measuring cognitive insight in schizophrenia and bipolar disorder: a comparative study. BMC Psychiatry.P. 7, 71.

[23]. Erikson M and Lysaker P. (2016): Self esteem and insight as predictors of symptom change in schizophrenia: A longitudinal study. Clinical Schizophrenia \& Related Psychoses. July 2012.

[24]. Fannon D, Hayward P, Thompson N, Green N, Surgulaze S, Wykes T. (2009): The self or the voice? Relative contribution of self esteem and voice appraisal in persistent auditory hallucinations. Schizophrenia Research, 112:P.p. 174- 180.

[25]. Ghaznavi S, Deckersbach T. (2012): Rumination in bipolar disorder: evidence for an unquiet mind. iology of Mood \& Anxiety Disorders2012 P.2:2

[26]. Ghaznavi SH, Deckersbach TH. (2012): Rumination in bipolar disorder: evidence for an unquiet mind. Biology of Mood \& Anxiety Disorders2012P. 2:2

[27]. Hayward P, Wong G, Bright J, Lam D (2002): Stigma and self esteem in manic depression: An exploratory study. Journal of Affect Disorders, 69, P.p. 61:67.

[28]. Heatherton T, Polivy J. (1991). Development and validation of a scale for measuring state self-esteem. Journal of Personality and Social Psychology, 60, P.p. 895-910.

[29]. Hilt L, McLaughlin K, Nolen-Hoeksema S. (2010): Examination of the Response Styles Theory in a Community Sample of Young Adolescents. Journal of Abnormal Child Psychology ; 38(4):P. 545-56.

[30]. Johnson S, McKenzie G, McMurrich S. (2008): Ruminative Responses to Negative and Positive Affect Among Students Diagnosed with Bipolar Disorder and Major Depressive Disorder. Cognitive Therapy and Research. 32:P.p. 702-713.

[31]. Johnson SH, McKenzie G, McMurrich S. (2008): Ruminative Responses to Negative and Positive Affect Among Students Diagnosed with Bipolar Disorder and Major Depressive Disorder. Cognitive Therapy Research. Oct 1; 32(5):P.p. 702-713.

[32]. Kumari R, Chaudhury S, Kumar S. (2013): Dimensions of hallucination and delusions in affective and non- affective illness. ISRN. Available at: https://www.ncbi.nlm.nih.gov/pmc/articles/PMC3755384/

[33]. Meaden A, Keen N, Aston R, Barton K, Bucci S. (2013): Cognitive therapy for command hallucinations. London. Routledge.

[34]. Nilsson K, Jorgensen C, Craig T, Straarup K, Licht R. (2010): Self esteem in remitted bipolar disorder patients: A Meta analysis. Bipolar Disorders, 12:P.p. 585:592.

[35]. Nolen-Hoeksema S. (1991): Responses to depression and their effects on the duration of depressive episodes. Journal of Abnormal Psychology ; 100:P.p.569-582.

[36]. Owens T, Stryker SH, Goodman N. (2006): Extending Self-Esteem Theory and Research: Sociological and Psychological Currents. Cambridge University Press, Psychology - P. 472 pages.

[37]. Pardoen D, Bauwen F, Tracy A, Martin F, Mendlewicz J. (1993): Sels esteem in recovered bipolar and unipolar outpatients. British 
Journal of Psychiatry. 159,P.p. 239:244.

[38]. Park J, Ryu, V, Ha R, Lee S, Choi WJ, Ha K. (2014): Assessment of implicit self-esteem in bipolar manic and euthymic patients using the implicit association test. Psychiatry 55.3 (Apr 2014):P. 557-64.

[39]. Pavlickova H, Varese F, Smith A, Myin-Germeys I, Turnbull OH, Emsley R, Bentall RP. (2013): The dynamics of mood and coping in bipolar disorder: longitudinal investigations of the inter-relationship between affect self-esteem and response styles. PLoS One; 8(4): e62514

[40]. Pavlickova H, Turnbull OH, Myin-Germeys I, Bentall RP. (2015): The inter-relationship between mood, self-esteem and response styles in adolescent offspring of bipolar parents: an experience sampling study. Psychiatry Research. 2015 Feb 28; 225(3):P.563-70.

[41]. Pavlickova H1, Turnbull OH, Bentall RP. (2014): Discrepancies between explicit and implicit self-esteem and their relationship to symptoms of depression and mania. Psychol Psychother. 2014 Sep; P.87(3)

[42]. Perich T, Manicavasagar V, Mitchell PB, Ball JR. (2011): Mindfulness, response styles and dysfunctional attitudes in bipolar disorder. Journal of Affect Disorders. 2011 Nov;134(1-3): P.126-32.

[43]. Peters E, Williams S, Cooke M, Kuipers E. (2012): It's not what you hear, it's the way you think about it: Appraisal as determinants of affect and behavior in voice hearer. Psychiatric Medicine, 42:P.p. 1507- 1514.

[44]. Riggs S, Grant P, Perivoliotis D, and Beck A. (2012): Assessment of Cognitive Insight: A Qualitative Review. Schizophrenia Bulletin. Retrieved from: http://schizophreniabulletin.oxfordjournals.org/content/early/2010/08/06/schbul.sbq085.full

[45]. Roelofs J, Rood L, Meesters C, Dorsthorst V, Bögels S, Alloy L, and Nolen-Hoeksema S. (2010): The influence of rumination and distraction on depressed and anxious mood: A prospective examination of the Response Styles Theory in children and adolescents. Eur Child Adolescent Psychiatry. 2009 Oct; 18(10):P.p. 635-642.

[46]. Rosenberg M. (1965): Society and the adolescent self-image. Princeton, NJ: Princeton University Press. Available at: http://fetzer.org/sites/default/files/images/stories/pdf/selfmeasures/self_measures_for_self-esteem_rosenberg_self-esteem.pdf.

[47]. Silveira E, Kauer-Sant'Anna M. (2015): Rumination in bipolar disorder: a systematic review. Rev. Bras. Psiquiatr. vol.37 no.3 São Paulo July/Sept. 2015

[48]. Smith B, Fowler D, Freeman D, Bebbington P, Bashforth H, Garety P, Kuipers E. (2006): Emotions and psychosis: Links between depression, self esteem, negative schematic beliefs and delusions and hallucinations. Schizophrenia Research, 86: P.p. $181-188$

[49]. Story A. (2004): Self-Esteem and Self-Certainty: A Mediational Analysis. European Journal of Personality . 18:P.p. 115-125.

[50]. Thomas J, Bentall R. (2002): Hypomanic traits and response styles to depression. British Journal of Clinical Psychology, 41(3), P.p. 309-314.

[51]. Thomas J1, Knowles R, Tai S, Bentall RP. (2007): Response styles to depressed mood in bipolar affective disorder. Journal of Affect Disorders., 100(1-3): P. 249-52.

[52]. Van der Gucht E, Morriss R,Lancaster G, Kinderman P, Bentall RP (2009): Psychological processes in bipolar affective disorder: negative cognitive style and reward processing. The British Journal of Psychiatry. 194: P.p. 146-151.

[53]. Warman D, Lysaker P, Leutdk B, Martin J. (2010): Self-esteem and delusion proneness. Journal of Nervous Mental Disorders. 2010 Jun;198(6):P. 455-7.

[54]. Warman D, Lysaker P.(2011): Delusional ideation and self-esteem in individuals with psychotic disorders. J Nerv Ment Dis. 2011 Jan;199(1):P.p. 58-61.

[55]. Warman D, Lysaker P, Martin J. (2007): Cognitive insight and psychotic disorder: the impact of active delusions. Schizophrenia Research; 90: P.p.325-333.

[56]. Werf- Eldering VD, Meer VD, Holthausen B and Aleman N. (2011): Insight in bipolar disorder: associations with cognitive and emotional processing and illness characteristics. Bipolar Disorder J. 2011 Jun; 13(4): P.343-54.

[57]. Yen C, Chen $\boldsymbol{C}$, Ko C, Yen H, Huang $\boldsymbol{C}$. (2007): Changes in insight among patients with bipolar I disorder: a 2-year prospective study. Bipolar Disorders. 2007 May;9(3):P.238-42.

[58]. Yen C, Chen C, Yeh M, Ker J, Yang S, Yen J. (2004): Correlates of insight among patients with bipolar I disorder in remission. Journal of Affect Disorders. 2004 Jan;78(1):P.p. 57-60 